\title{
Delayed recovery of renal function in patients with acute renal failure due to accelerated hypertension
}

\author{
M. Yaqoob, P. McClelland and R. Ahmad \\ Regional Renal Unit, Royal Liverpool Hospital, Liverpool, UK
}

\begin{abstract}
Summary: Five patients with acute renal failure due to accelerated hypertension required regular dialysis treatment for 2-12 months (mean 8.8), before recovering sufficient renal function for dialysis to be withdrawn. Two patients who had prior evidence of chronic renal impairment remained off dialysis for 20 and 27 months before decompensating again to require regular dialysis treatment. Two patients with no prior history of renal disease have remained independent of dialysis for 32 and 48 months. The fifth patient was lost to follow-up after a 7 month dialysis-free period.

Delayed recovery of renal function following accelerated hypertension is a distinct possibility and should be considered in such patients before contemplating long term strategies such as renal transplantation.
\end{abstract}

\section{Introduction}

Accelerated (malignant) hypertension is a rare cause of acute renal failure (ARF) with an estimated incidence of one patient per million population per year. ${ }^{1}$ Delayed recovery of renal function after regular dialysis treatment (RDT) is established, has previously been described ${ }^{1-12}$ and is attributed to good control of blood pressure. This syndrome is characterized by normal sized kidneys with marked vascular changes and well preserved glomeruli on renal histology. ${ }^{2}$ The incidence of accelerated hypertension is similar on this unit and our series now includes 5 cases of ARF who fulfilled the WHO criteria for malignant hyperten$\operatorname{sion}^{13}$ and required RDT who subsequently recovered their renal function. Further details of these patients will be presented in this paper.

\section{Patients and methods}

The Royal Liverpool Hospital is the regional renal unit serving a population of approximately two million. Sixty to seventy cases of ARF requiring dialysis are referred each year to the unit. Between July 1982 and January 1987 five cases of acute oliguric renal failure due to accelerated hypertension were treated and these cases are reported in greater detail. During this period 6 other patients, presenting with accelerated hypertension and varying degrees of renal failure but dialysis-

Correspondence: M. Yaqoob, M.R.C.P., 6z Link Unit, Royal Liverpool Hospital, Prescot Street, Liverpool L7 8XP, UK

Accepted: 18 February 1991 independent, were also treated on the unit and their clinical details are compared with the ARF group in Table $\mathbf{I}$.

\section{Case reports}

Case No. 1

A 44 year old Caucasian policeman, whilst on holiday in Spain, presented to a local hospital with headache, visual impairment, dyspnoea and renal failure. A year earlier he had been investigated for hypertension and renal impairment, plasma urea $16.8 \mathrm{mmol} / \mathrm{l}$ and creatinine $258 \mu \mathrm{mol} / \mathrm{l}$. A renal biopsy was performed which confirmed hypertensive nephrosclerosis and subsequently his blood pressure was well controlled on atenolol $100 \mathrm{mg}$ daily. On this admission his blood pressure was $250 / 1.70 \mathrm{mmHg}$, he had grade IV hypertensive retinopathy, pulmonary oedema and oliguria. His plasma creatinine was $1408 \mu \mathrm{mol} / \mathrm{l}$, peritoneal dialysis was instituted and he was transferred to our unit where he commenced regular haemodialysis treatment. After 10 months on RDT, recovery of renal function was evident and dialysis was stopped. His blood pressure was now controlled with hydralazine and labetalol therapy. Six months after stopping dialysis treatment his creatinine clearance was $28 \mathrm{ml} / \mathrm{min}$. He remained dialysis-independent for 20 months but during this time, despite satisfactory blood pressure control, he developed proteinuria up to $1.2 \mathrm{~g} /$ day in association with progression to end stage renal failure. He recommenced RDT but died 6 months later following a myocardial infarction. 
Table I Summary of patients with accelerated hypertension

\begin{tabular}{|c|c|c|c|c|c|c|c|}
\hline Patient & Age & Sex & Smoker & Urinalysis & $\begin{array}{c}\text { Serum } \\
\text { creatinine } \\
(\mu \mathrm{mol} / \mathrm{l})\end{array}$ & $\begin{array}{c}\text { Combined renal } \\
\text { size } \\
(\mathrm{cm})\end{array}$ & Outcome \\
\hline \multicolumn{8}{|c|}{ Accelerated hypertension and acute oliguric renal failure } \\
\hline 1. & 44 & $\mathbf{M}$ & + & $\mathrm{p}+++, \mathrm{b}++$ & 1408 & 24 & HD $10 \mathrm{mths}$ \\
\hline 2. & 48 & $\mathbf{M}$ & + & $\mathrm{p}+++, \mathrm{b}+++$ & 918 & 23 & CAPD $12 \mathrm{mths}$ \\
\hline 3. & 50 & $\mathbf{M}$ & + & $\mathrm{p}+++, \mathrm{b}+++$ & 1430 & 23 & HD 2 mths \\
\hline 4. & 43 & $\mathbf{M}$ & + & $\mathrm{p}+++, \mathrm{b}+++$ & 965 & 22 & CAPD $12 \mathrm{mths}$ \\
\hline 5. & 55 & $\mathbf{M}$ & + & $\mathrm{p}+++, \mathrm{b}+++$ & 1669 & 24 & HD 8 mths \\
\hline \multicolumn{8}{|c|}{ Accelerated hypertension and polyuric renal failure } \\
\hline 6. & 40 & $\mathbf{M}$ & - & $\mathrm{p}+++, \mathrm{b}++$ & 892 & 14 & RDT $17 \mathrm{mths}$ \\
\hline 7. & 61 & $\mathbf{M}$ & + & $\mathrm{p}+++, \mathrm{b}+++$ & 570 & 20 & $\mathrm{CrCl}>10.6 \mathrm{yrs}$ \\
\hline 8. & 18 & $\mathbf{M}$ & - & $\mathrm{p}+++, \mathrm{b}+++$ & 685 & 17 & RDT 40 mths \\
\hline 9. & 33 & $\mathbf{M}$ & + & $\mathrm{p}+++, \mathrm{b}+++$ & 323 & 24 & $\mathrm{CrCl}>75.7 \mathrm{yrs}$ \\
\hline 10. & 44 & $\mathbf{F}$ & - & $\mathrm{p}+++, \mathrm{b}+++$ & 850 & 22 & $\mathrm{CrCl}>50.3 \mathrm{yrs}$ \\
\hline 11. & 53 & $\mathbf{M}$ & + & $\mathrm{p}+++, \mathrm{b}+++$ & 752 & 18 & RDT 6 mths \\
\hline
\end{tabular}

Summary of patients with accelerated hypertension. M, male; F, female; + , smoker; - , non-smoker. Urinalysis on dipstick testing at presentation; $p$, proteinuria; $b$, haematuria. Outcome for oliguric renal failure refers to months స్ (mths) spent on haemodialysis (HD) or continuous ambulatory peritoneal dialysis (CAPD) before recovery of renal function. Outcome for polyuric renal failure refers to the need for regular dialysis treatment (RDT) or the latest creatinine clearance in $\mathrm{ml} / \mathrm{min}$, months (mths) or years (yrs) after presentation respectively.

\section{Case No. 2}

A 48 year old male Caucasian manual worker first presented in 1976 with nephrotic syndrome and hypertension. Renal biopsy at the time revealed membrano-proliferative glomerulonephritis with additional hypertensive changes. His blood pressure was controlled on labetalol and he was followed up in the out-patient's department. Seven years after presentation his plasma creatinine rose acutely to $918 \mu \mathrm{mol} / 1$, his blood pressure was $240 / 140 \mathrm{mmHg}$ with evidence of accelerated hypertension and he was in left ventricular failure. He stabilized on continuous ambulatory peritoneal dialysis (CAPD) and after 12 months RDT recovery of renal function was evident making dialysis unnecessary. His blood pressure control was satisfactory throughout with atenolol and prazosin and a year later his creatinine clearance was $12 \mathrm{ml} / \mathrm{min}$. Despite this he had persistent proteinuria of $2.7-3.8 \mathrm{~g} /$ day and after 27 months without dialysis he again developed renal failure requiring RDT, though he adapted well to this and remains well.

\section{Case No. 3}

This 50 year old male Caucasian was admitted to our unit with a 2-week history of headache, blurring of vision and dyspnoea. A year earlier, hypertension had been diagnosed and he was commenced on alpha methyl dopa. At presentation this time his blood pressure was $240 / 150 \mathrm{mmHg}$ and he had grade IV hypertensive retinopathy. In addition he was in left ventricular failure ang oliguric. The initial investigations confirmed the $\overrightarrow{0}$ he was in renal failure with a plasma creatinine $1430 \mu \mathrm{mol} / 1$. Abdominal sonography demonstra ted normal sized kidneys and renal biopsy showed only changes of hypertensive nephrosclerosis. After 2 months on RDT, renal recovery was noticed and dialysis treatment was stopped. His blood pressure is now controlled with labetalol, prazosin and enalapril. Forty-eight months later he remains dialysis-independent with a creatinine clearance of $24 \mathrm{ml} / \mathrm{min}$ and proteinuria less than $0.5 \mathrm{~g} /$ day.

\section{Case No. 4}

This 43 year old Nigerian marine engineering student was admitted to the unit with a 6-week history of headache, blurring of vision and dyspnoea. Three years earlier his medical practitioner diagnosed hypertension and he was prescribed atenolol. On admission he had accelerated hyper- N tension, oliguria and a plasma creatinine of $N$ $965 \mu \mathrm{mol} / 1$. Ultrasound examination revealed nor- N mal sized kidneys, he commenced peritoneal dia- $\omega$ lysis and was maintained by CAPD therapy. Twelve months later recovery of renal function was

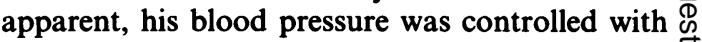
atenolol and minoxidil and he has remained well for 32 months, his creatinine clearance has risen to $69 \mathrm{ml} / \mathrm{min}$ and he has no proteinuria. 
Case No. 5

A 55 year old Nigerian motor mechanic was admitted to our unit with a 5-week history of nausea, vomiting, loss of appetite, lethargy and exertional dyspnoea. Three years earlier his medical practitioner had diagnosed hypertension and he was prescribed atenolol although his compliance was questionable. On admission he had evidence of accelerated hypertension and he was oliguric with a plasma creatinine of $1669 \mu \mathrm{mol} / 1$. An intravenous urogram showed normal sized kidneys with no evidence of obstruction or renovascular disease. He commenced RDT and after a period of 8 months renal recovery was apparent. Blood pressure control whilst on RDT and thereafter, was achieved by atenolol and minoxidil therapy. His renal function progressively improved and 7 months after stopping dialysis he was lost to follow-up; his plasma creatinine at that time was $370 \mu \mathrm{mol} / 1$.

\section{Discussion}

In all 5 patients, blood pressure was rigorously controlled, which we believe is an important factor in promoting renal recovery. Haemodialysis was used in 3 cases and peritoneal dialysis in 2 , so the mode of RDT did not appear to influence recovery of renal function. Enhanced recovery of renal function has been reported with peritoneal dialysis. ${ }^{1}$ It is plausible that better blood pressure control and the steady metabolic state that occurs with peritoneal dialysis, ${ }^{14}$ may have additional therapeutic effect but in our series the patients treated by haemodialysis recovered renal function slightly earlier than in the peritoneal dialysis patients.

Two of the five patients were African, which is in keeping with the increased incidence of malignant hypertension in the negroid race. ${ }^{2-10,15}$ Although the blood pressure proved difficult to control in these patients, it was two of the Caucasians who subsequently decompensated to require further RDT. It seems likely that these two patients already had substantial renal damage before the onset of accelerated hypertension and in spite of the normal kidney size. These patients demonstrated increasing proteinuria during their recovery phase and this appears to predict declining renal function ${ }^{16}$ and may indicate a process of hyperfiltration in the remnant nephrons.

Previous reports suggest that a large proportion of patients in common with our own series have a past medical history of hypertension but few cases had documented evidence of impaired renal function before presentation with acute renal failure (usually a bad prognosis for renal recovery), so the transient renal recovery in cases 1 and 2 , both of whom had significant renal failure prior to ARF, is all the more encouraging.

Malignant or accelerated hypertension was first noted as a cause of ARF in $1931,{ }^{17}$ but the first report of short term recovery was not recorded until $1971,{ }^{3}$ after the availability of dialysis and effective anti-hypertensive drugs. Since the introduction of angiotensin converting enzyme (ACE) inhibitors and minoxidil, ${ }^{18-20}$ several more reports have confirmed the potential for recovery of renal function. $1,2,4-12$

All 5 patients had oliguria at presentation which is regarded as a useful predictor of recovery, ${ }^{2}$ as oliguria may be due to acute tubular necrosis. The kidney size is usually normal, as in these cases, and a combined renal length of greater than $18 \mathrm{~cm}$ at presentation is considered to be predictive of recovery of renal function. ${ }^{21}$ These findings are emphasized by comparison with 6 patients presenting in polyuric renal failure and accelerated hypertension. Males again predominated, though all of these patients were Caucasian. Only half of these patients smoked compared to all the patients in oliguric renal failure. All patients in both groups had microscopic haematuria and proteinuria on dipstick testing. Even amongst the polyuric group renal size was important, with a combined renal size of over $18 \mathrm{~cm}$ providing a better prognosis. Three such patients with normal sized kidneys are still dialysis-independent but the remaining 3 patients with combined renal lengths of $18 \mathrm{~cm}$ or less developed end stage renal disease 6,17 and 40 months after presentation and are now on RDT (see Table I). As can be seen from Table I these patients presented with advanced renal impairment. It is surprising that the requirement for RDT was delayed for so long but, again, may suggest a role for effective anti-hypertensive therapy in preserving renal function.

We conclude that in patients presenting with accelerated hypertension, normal sized kidneys and oliguric renal failure requiring dialysis treatment, recovery of renal function is possible provided that long term dialysis is also supported with good blood pressure control. We therefore suggest, that in such cases, it would be worthwhile deferring renal transplantation for at least 12 months, whilst delayed recovery of renal function remains a distinct possibility. 


\section{References}

1. Isles, C.G., McLay, A. \& Boulton-Jones, J.M. Recovery in malignant hypertension presenting as acute renal failure. $Q J$ Med 1984, 212: 439-452.

2. Mamdani, B.H., Lim, V.S., Mahurkar, S.D., Katz, A.J. \& Dunea, G. Recovery from prolonged renal failure in patients with accelerated hypertension. N Engl J Med 1974, 292: 1343-1344.

3. Sevitt, L.H., Evans, D.J. \& Wong, O.M. Acute oliguric renal failure due to accelerated (malignant) hypertension. $Q \mathrm{~J} \mathrm{Med}$ 1971, 157: 127-144.

4. Eknoyan, G. \& Siegel, M.B. Recovery from anuria due to malignant hypertension. JAMA 1971, 215: 1122-1125.

5. Bischel, M.D., Gans, D.S. \& Barbour, B.H. Bilateral nephrectomy for hypertension. Ann Intern Med 1972, 77: 656-657.

6. Barcenas, C.G., Eigenbrodt, E., Long, D.L. \& Hull, A.R. Recovery from malignant hypertension with anuria after prolonged haemodialysis. South Med J 1976, 69: 1230-1233.

7. Bacon, B.R. \& Ricanati, E.S. Severe and prolonged renal insufficiency: reversal in a patient with malignant hypertension. JAMA 1978, 239: 1159-1160.

8. Luft, F.C., Bloch, R., Szwed, J.J., Grim, C.M. \& Grim, C.E. Minoxidil treatment of malignant hypertension: recovery of renal function. JAMA 1978, 240: 1985-1987.

9. Mitchell, H.C., Graham, R.M. \& Pettinger, W.A. Renal function during long term treatment of hypertension with minoxidil: comparison of benign and malignant hypertension. Ann Intern Med 1980, 93: 676-681.

10. Cordingley, F.T., Jones, N.F., Wing, A.J., \& Hilton, P.J. Reversible renal failure in malignant hypertension. Clin Nephrol 1980, 14: 98-103.

11. Adelman, R.D. \& Russo, J. Malignant hypertension: recovery of renal function after treatment with anti-hypertensive medications and haemodialysis. J Pediatr 1981, 98: 766-768.
12. Bahir, F.A.A., Basilinki, N. \& Dunea, G. Transient and sustained recovery from renal shut down in accelerated $C$ hypertension. Am J Med 1986, 80: 172-176.

13. Report of a WHO expert committee. Arterial hypertension $\overrightarrow{\overline{\vec{\omega}}}$ technical report series. 1978, 68: 29-30.

14. Amair, P., Khanna, R., Leibel, B. et al. Continuous ambulatory peritoneal dialysis in diabetics with end stage $\frac{\bar{\sigma}}{\bar{A}}$ renal failure. N Engl J Med 1982, 306: 625.

15. Milne, F.J., James, S.H. \& Veriava, Y. Malignant hyperten- $\overparen{\overparen{D}}$ sion and its renal complications in black South Africans. $S$ 으 Afr Med J 1989, 76: 164-167.

16. Williams, P.S., Fass, G. \& Bone, J.M. Renal pathology and proteinuria determine progression in untreated mild $/ \mathrm{mod}-\vec{O}$ erate chronic renal failure. $Q J$ Med 1988, 252: 343-354.

17. Klemperer, P. \& Otani, S. Malignant nephrosclerosis. Arch $\vec{\omega}$ Pathol 1931, 11: 60-117.

18. Mackay, A., Isles, C., Henderson, I., Fife, R. \& Kennedy, C. Minoxidil in the management of intractable hypertension. $Q 3$ $J$ Med 1981, 50: 175-190.

19. Atkinson, A.B., Brown, J.J., Lener, A.F. \& Robertson, J.I.S. ? Combined treatment of severe intractable hypertension with captopril and diuretic. Lancet 1980, ii: 105-108.

20. Martinez-Fernandez, R., Fernandez-Rodriguez, R., Lizas- $\infty$ oain-Hernandez, M., Praga-Terente, M., Alcazar de la Ossa, J.M. \& Rodicio-Diaz, J. Captopril in essential malignant arterial hypertension with renal insufficiency. Rev Clin Esp 1988, 183: 1984-1989.

21. Nicolson, G.D. Long term survival after recovery from $\mathcal{S}$ malignant nephrosclerosis. Am J Hypertens 1988, 1: 73-75. 